\title{
Comparative Study of Nasij and Jin Duan zi of Mongol Period
}

\author{
Huiwei Mao ${ }^{1}$ \\ ${ }^{1}$ Institute of Culture, Zhejiang Fashion Institute of Technology, Ningbo, Zhejiang, China \\ Correspondence: Huiwei Mao, Institute of Culture, Zhejiang Fashion Institute of Technology, Ningbo, Zhejiang, \\ 315211, China. E-mail: 19835602@qq.com
}

Received: January 16, $2020 \quad$ Accepted: March 28, $2020 \quad$ Online Published: April 30, 2020

doi:10.5539/ass.v16n5p13

URL: https://doi.org/10.5539/ass.v16n5p13

\begin{abstract}
The Mongols created exceptionally sumptuous cloths of gold to symbolize their imperial authority and legitimacy, what was known at that time as Nasij or Jin Duan zi. They were developed from different culture and textile system. Nasij was an innovation from Central Asia, the technique attests to the mass movement of weavers from the eastern Iranian world to China during the Mongol period. As for Jin Duan zi, it's a traditional Chinese textile. Under the special background of Yuan Dynasty, the design of both Nasij and Jin Duan zi have combined eastern and western elements.
\end{abstract}

Keywords: Nasij, Jin Duan zi, Mongol and Yuan Dynasty, Sino-western fuse

Mongol taste for luxury was equated with gold, gold brocade was treasured by the Mongol elite and rulers, the luxury silk was symbol of imperial authority, power, and legitimacy. During Mongol and Yuan Dynasty, what was known at the time for "gold brocade", as Nasij (纳石失) or Jin Duan zi (金段子) or Jin Da zi (金搭子). These names mentioned in different documents, but no details are given to distinguish them and always silent on what their technical characteristics were. Professor Zhao feng and Shang gang has carried out some relevant research. Professor Zhao based on the material object (Zhao, 2006, pp. 85-96), while Professor Shang in view of the documents (Shang, 1999, pp. 91-92). This paper is based on the research of the above two professors and try to compare the Nasij and Jin Duan zi from three parts: First, the origin of the name,Second, the technical analysis and Third the styles and motifs.

\section{The Origin of the Name}

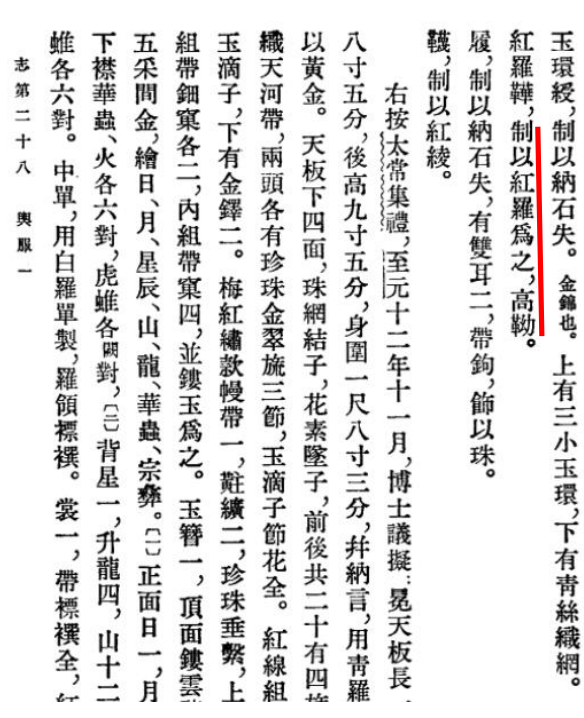

Figure 1. Book of Yuan shi

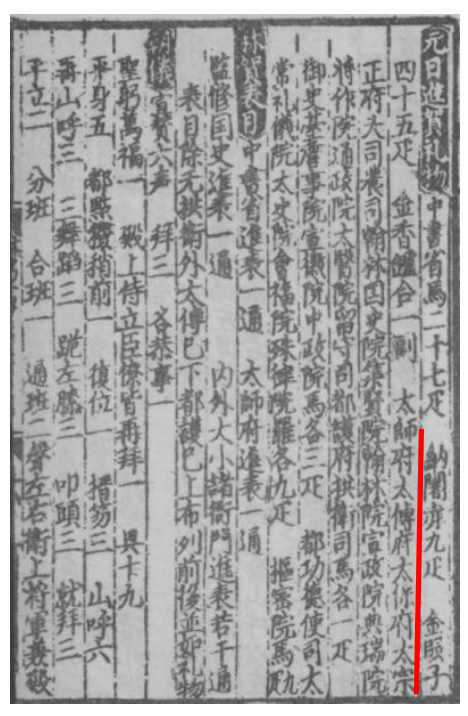

Figure 2. Book of Shi Lin Guang Ji

Nowadays, we can find Nasij (纳石失, 纳阇赤, 纳失失) or Jin Duan zi (金段子) from Yuan shi (元史 History of the Yuan Dynasty) (Figure 1), Shi Lin Guang Ji (事林广记 Folk Book of Daily Encyclopedia) and The Travels of Marco Polo and so many documents. So it's almost certain Nasij and Jin Duan zi were both popular in Yuan 
Dynasty and they are different types, because they have independent title in historical materials and people in Yuan dynasty have separated them and listed them separately as the book Shi Lin Guang Ji shows (Figure 2). In the book of History of the Yuan Dynasty, the editor is giving explanatory notes to Nasij and explain it was a kind of gold brocade, but no further details. Apparently, Nasij is a foreign name, today the common view point is the name Nasij is Persian transliteration, but its origin is Arabic. It was an innovation from Central Asia, this technique attests to the mass movement of weavers from the eastern Iranian world to China during the Mongol period. As for Jin Duan zi, it is a traditional Chinese name almost certainly.

\section{Technical Analysis}

In Chinese documents, little details on the technical characteristics about the two gold brocade, there is a sentence from Dao yиan xие gu lu (道园学古录), which is written by $\mathrm{Yu} \mathrm{Ji}$, who served at the Yuan imperial court. It is said Nasij is woven with strips of gilded leather. It should be a method of making gold thread (Yu, 1937, p. 400). It would thus seem that leather, or some other kind of animal substrate, was used in China for weaving Nasij into the fourteenth century. No matter Nasij or Jin Duan zi woven with gold thread, there are two kinds of gold thread, one is flat gold and the other is wrap gold (Figure 3) The gold is on a paper substrate associated with Asia, whereas animal skin substrates were used in Islamic lands. On technical analysis, the most important difference is in general, yes, in general, the textile weave of Nasij is lampas, it characteristically consists of two warp systems: a decided ground warp and a binding warp. In addition, two or more weft systems were used. The pattern wefts are bound by the extra binding warp forming a binding weave (Figure 4). The true lampas probably took place in Iran in the centuries before the year 1000, and it was carried westward by the Arabs in the Middle ages and the technique remained the same as in Yuan dynasty (Folsach \& Bersted, 1993, p. 75). By comparison, the basic weave of Jin Duan zi is weave with supplementary wefts, and the ground warp also used to bind the supplementary wefts. The supplementary golden wefts are woven into the foundation weave in specific areas required by the pattern and the golden weft can continuous or discontinuous (Figure 5). This weave structure is considered as traditional Chinese weave and has been found on silk fabrics during Tang Dynasty (Zhao, 2005, p. 294). As it's Chinese traditional fabric, Jin Duan zi may more popular in south of China during Yuan dynasty, as the book Lao qida (老乞大 Chinese textbooks written for the Koryo and Li Chao people) record, Jin Duan zi come from Jiang nan (Zheng, 2002, p. 151).

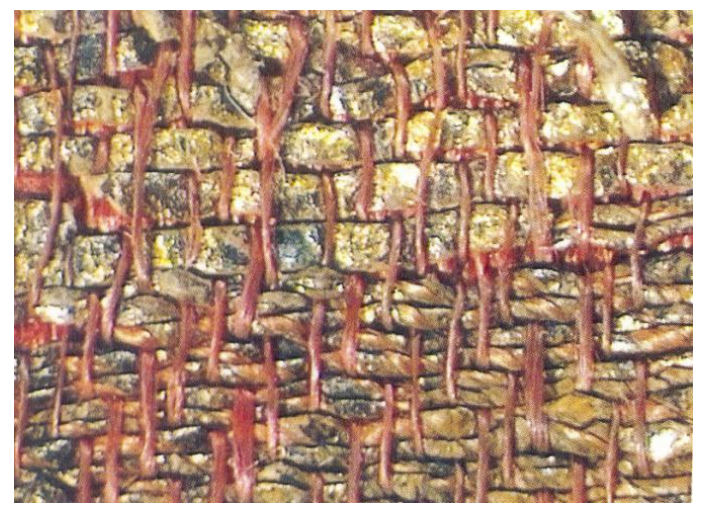

Figure 3. Flat gold and Warp gold

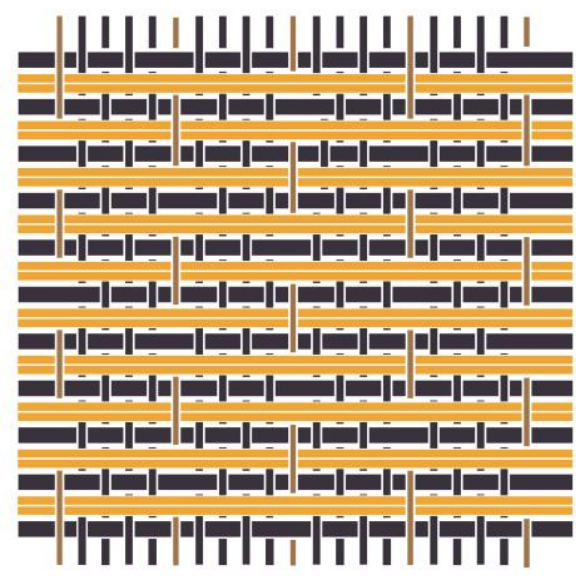

Figure 4. Lampas weave

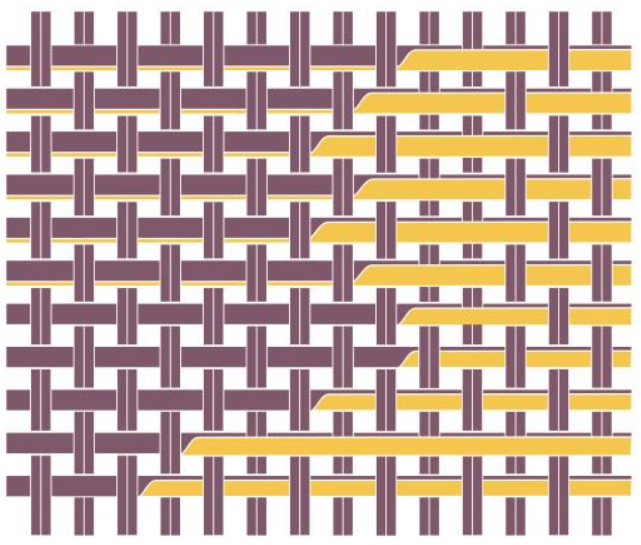

Figure 5. Weave with supplementary wefts 


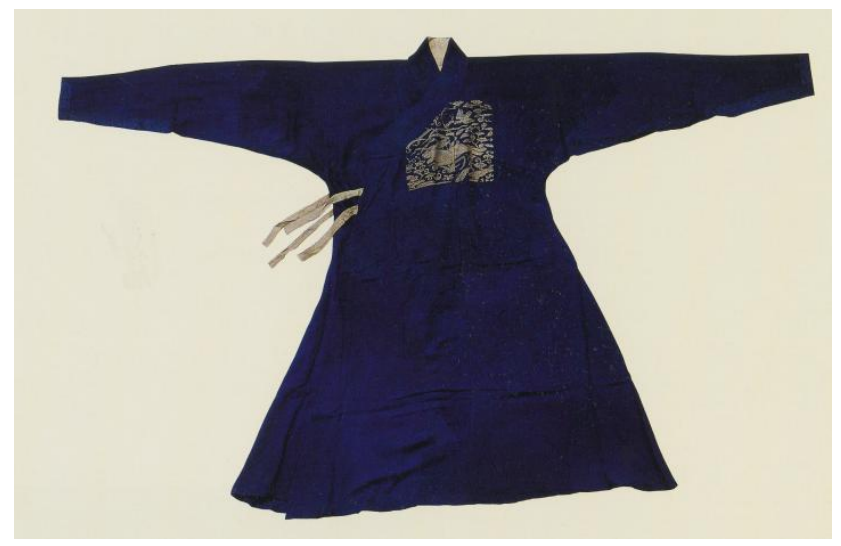

Figure 6. Robe with badge with falcon chasing hare, Private collection

Technical analysis of the textiles reveals some differences and subgroups. We encountered several special weaves. The gold brocade are based on the weave with supplementary wefts, but adding an extra binding warp such as this robe (Figure 6). The robe has an overlapping collar with right over left, narrow sleeves and wide skirt. In the front of the robe, there is a woven badge in good condition. The pattern consists of a hare in the center, a flying falcon on top right corner, and clouds and flowers around. It is a hunting scene and reflects on the rich style of Mongolian life. The weave of the robe is very interesting. Its ground fabric, except the badge, is twill damask, $1 / 2 \mathrm{~S}$ twill pattern on $2 / 1 \mathrm{Z}$ twill ground forming a peony scroll pattern. However, within the badge area, an extra binding warp is used to bind the supplementary golden threads, which lost all the gold foil, but left the Z-twisted silk core, forming a lampas weave: proportion: 1 binding warp to 3 foundation warps, 1 patterning weft to 1 foundation weft, and the binding warps were all cut at the back. Unfortunately, the badge on the back side is missing now (Zhao, 2005, pp. 50-51). So why the weaver weave it like this? The appearance of this special structure may be due to the fact that the ground warp of the fabric is blue, if the ground warp is directly binding with gold thread, the color is not harmonious enough, so the binding warp close to the color of gold thread is used for consolidation (Figure 7); it may also the attempt and innovation by the craftsman who is not familiar with the weave from Central Asia, but is very sure about the popularity of this structure. It is interesting to note that in recent years, another piece of fabric, almost identical to the badge of the robe, has appeared and is now collected in the China National Silk Museum (Figure 8). If the pattern of the fabric is identical, there are only differences in technology and color matching, which indicates that there were stock patterns for selection and repetition.

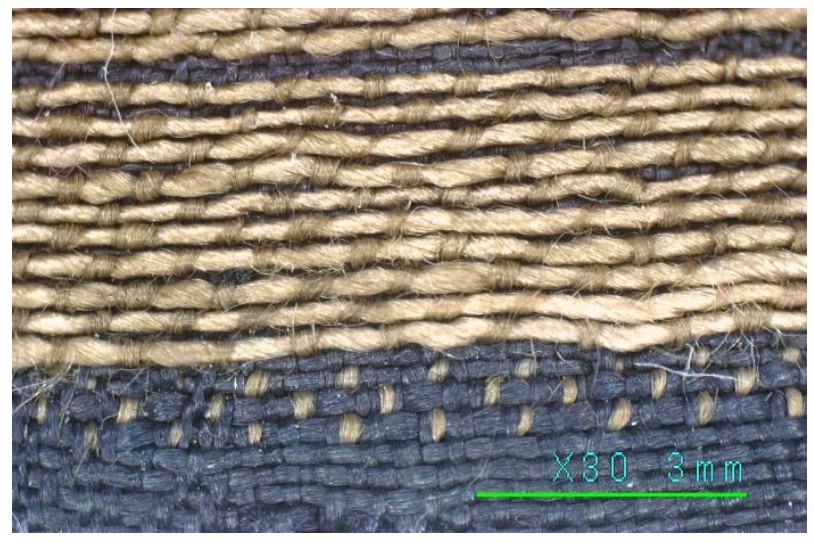

Figure 7. The weave of the robe badge

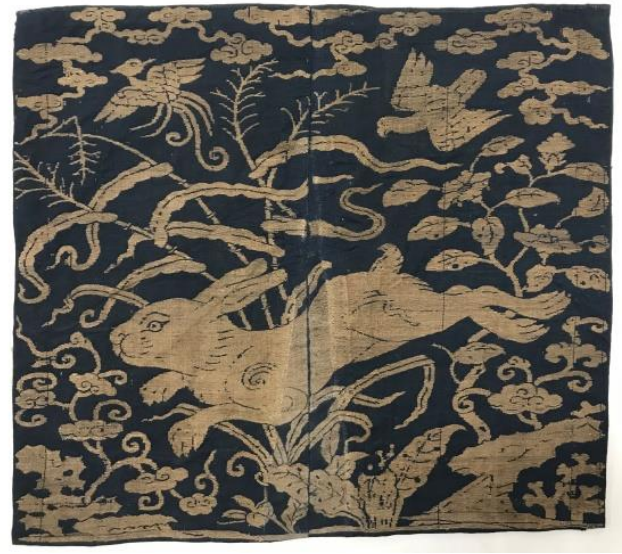

Figure 8. Badge, China National Silk Museum

\section{The Styles and Motifs}

The comparative on style and motifs may result in more confusion. As armies and merchant caravans, travelers, and missionaries traversed this vast region that linked the eastern Iranian world with China, goods-especially luxury silks-moved from one part of Asia to another, and with them the motifs with which they were woven (Watt \& Wardwell, 1997, p. 127). 


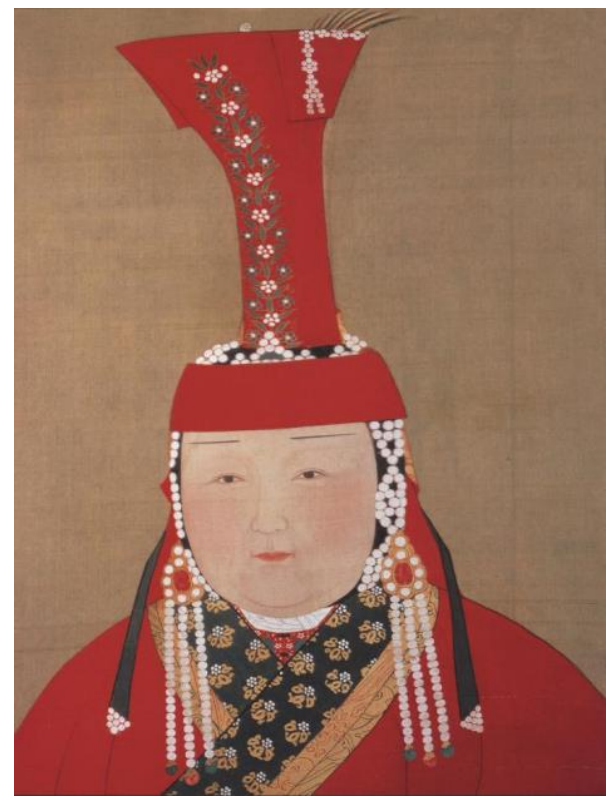

Figure 9. Chabi, Consort of Khubilai Khan.Yuan dynasty. National Palace Museum, Taipei

This is an image of Consort of Khubilai Khan (Figure 9), the collar of her robe should be made of Nasij, the motif is a kind of falcon (Figure 10), very similar like the one from Ming Shui Tomb (Figure 11). The patterns of falcon appeared in Tang Dynasty, many of them show the central and western Asian style. The patterns in Song and Yuan Dynasty basically inherited the style of Tang Dynasty, Many of them are in the form of antithetic, that is back to back and looking back to each other. As well as the form of double- headed eagles. It is admitted by all scholars that the double-headed eagle emblem functioned as a major symbol of power. Originated in the East, it was used in Mesopotamian art. But the falcon motifs on this image and the hood excavated from Ming Shui Tomb are different, they display like queue style. This kind of pattern with birds without a grid system seemed to be popular during the $13^{\text {th }}$ century.

The lampas collected in The Cleveland Museum of Art, design with Makaras, Phoenixes and Flowers (Figure 12), may woven in Central Asia or Dadu (present-day Beijing) in the $13^{\text {th }}$ century. In this silk, the designers drew from a wide variety of motifs, both imaginary and real. Rows of soaring phoenixes alternate with rows of makaras. Combining a fish body and tail, wings, and a dragon's head, the makara originated in India as a water creature. With the spread of Buddhism, the motif migrated into the art of Central Asia and, from there, into the art of northern China. The phoenixes, which is traditional Chinese motifs, soaring upward with wings outstretched, have crests, neck plumes, and long, serrated tail feathers. In the interstices are lotuses, tree peonies, and leaves (Watt \& Wardwell, 1997, p. 152). The phoenixes and flowers are Chinese, while the specific form of the peony was popular in North China before the arrival of the Mongols.

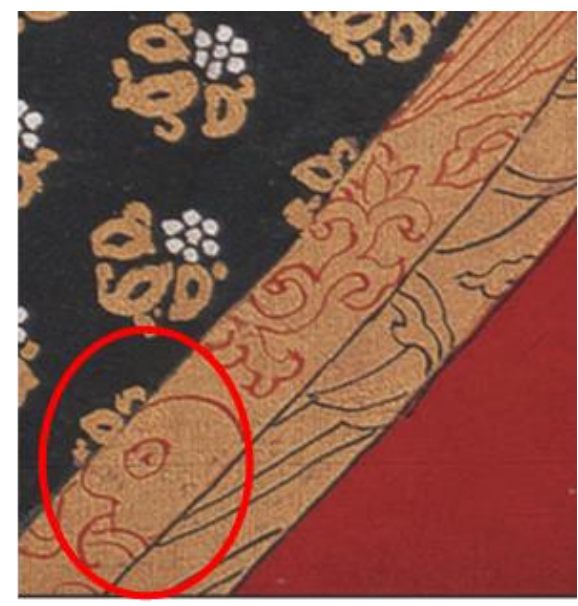

Figure 10. Detail of the image

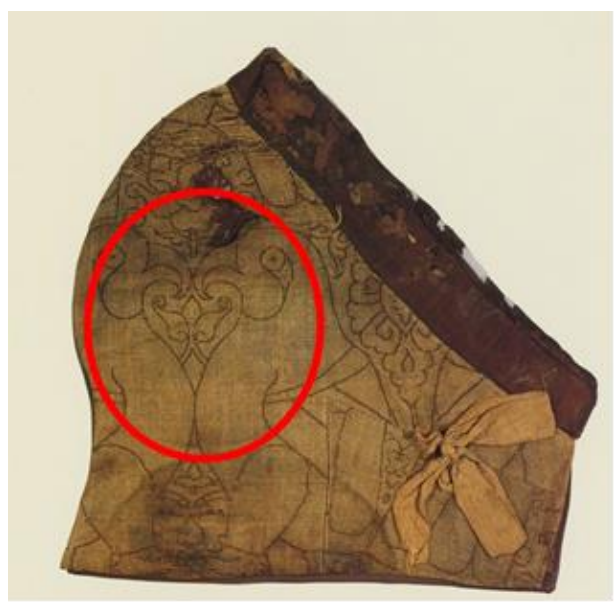

Figure 11. Hood with confronted falcons, Collection of Inner Mongolian Museum 


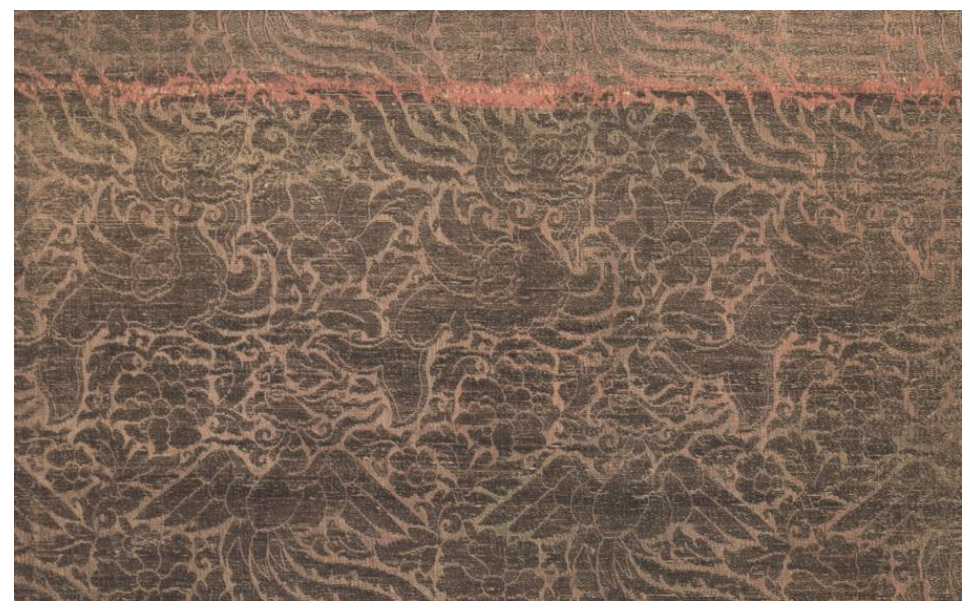

Figure 12. Makaras, Phoenixes and Flowers, Collection of The Cleveland Museum of Art

I have analyzed a hat which is an American private collection, the pattern on it is a running beast, and it gazing back and up at a round moon among clouds (Figure 13). This kind of animal pattern, which often matches the moon or the sun and the clouds, is a Central Asia antelope, called djeiran (Figure 14). The motif of the djeiran is commonly see on Chinese art of the Jin and Yuan dynasty. It is somewhat remarkable that the image of djeiran should have taken some five centuries to travel from Sogdiana to Jin China. But the weave of hat is twill foundation with supplementary wefts.

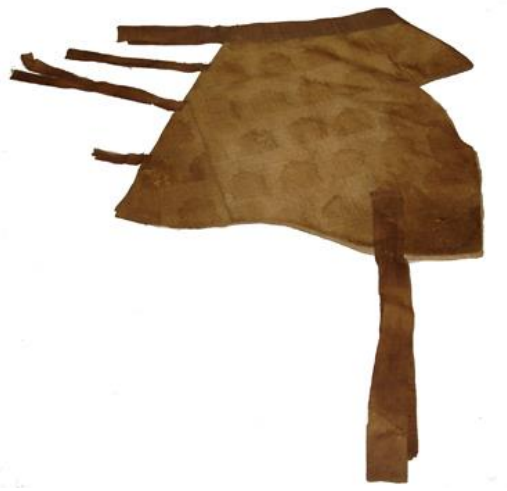

Figure 13. Gold brocade hat, private collection

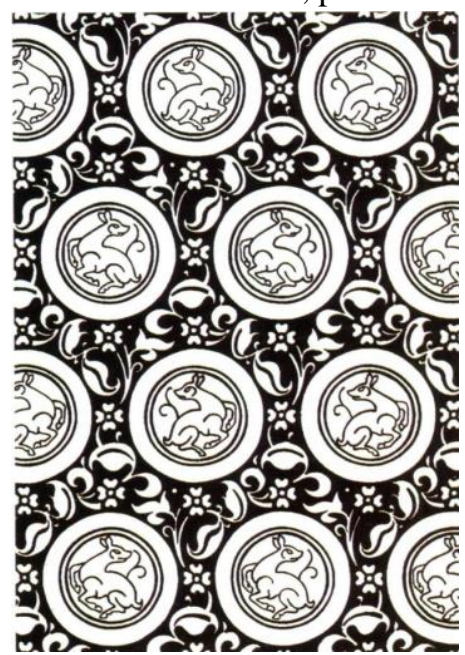

Figure 15. Reconstruction of the textiles with djeiran

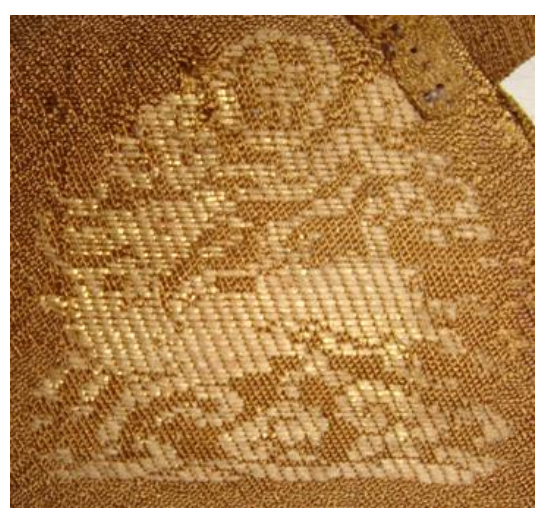

Figure 14. Pattern of djeiran

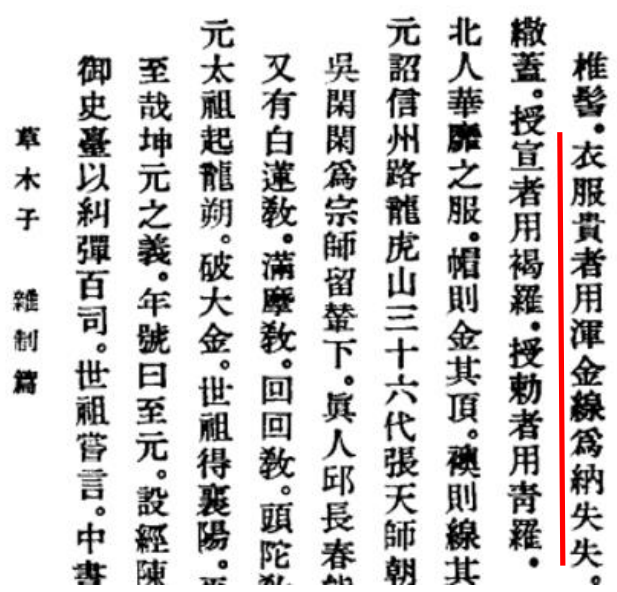

Figure 16. Book of Cao Muzi

Professor Zvezdana Dode has written a paper about the problem of ascription of Mongolian silks from the Golden Horde legacy, and one of the silk also with the djeiran (Figure 15). Through the analysis of pattern, her conclusion is it was a production of Central Asian craft shops. The reason is the pattern here shows 
comprehension of all necessary details of the composition by the weavers, that indicates its central Asian or Chinese origin. But the image of the antelope is encircled by the round medallion which was not typical for the Yuan dynasty (Dode, 2005, pp. 265-278). Patterns changed in the process, this is a common phenomenon.

In addition, the pattern units of the hat with djeiran arranged in scattered spot arrangement. This design fit the name record in the documents Jin Da zi (金搭子), because the Chinese character “搭” means “spot”, it's contrast with Nasij, which is gold-on-gold fabric, where both pattern and background were woven in gold thread, as the book “Cao mu zi” (草木子) writing, Nasij is woven with whole gold thread (衣服贵者用浑金线为纳失失) (Figure 16) (Ye, 1959, p. 61). The Chinese character “浑”, should mean a large area of gold thread, the surface of the fabric is all gold.

\section{Conclusion}

1). Nasij and Jin Duan zi were developed from different culture and textile system. Nasij was described as the most luxurious fabric, what both pattern and background were woven in differing types of gold thread, it was gold-on-gold textiles, as well as a kind of cloth with overall patterns woven in gold. In general, the textile weave of Nasij is lampas, it characteristically consists of two warp system and the motifs of Nasij often have a strong Western flavor, Such as pair of bird, pair of beast and double-headed bird. To Jin Duan zi, it was traditional Chinese textile and with offset motifs in gold in a plain background, it is may called Jin Da zi (金搭子) as well as the document record at that time. It express animal and plant patterns with strong Chinese style. And most patterns of JinDuanzi only have main motifs, without outline, which is different from Nasij.

2). The mixture of Islamic, Chinese and India design found in Nasij and Jin Duan zi, all reflect the mixed populations inhabiting together at that time. There is no way of knowing if these are indicative of widely separated weaving centers or of a variety of luxury textiles produced in a given area. We can see East-West and imperial-local joined, they gave rise to a specific artistic expression.

3). Under the special background of Yuan Dynasty, the design of both Nasij and Jin Duan zi have combined eastern and western elements. Especially the traditional Jin Duan zi is changed by adding a group of binding warp in the form of hanging, this may be the main way of Chinese lampas in Ming and Qing dynasties. So, since ancient times, the technology and culture between the East and the West has always been a two-way exchange, migration, trade and communication, which has influenced the process integration and cultural trend.

\section{Acknowledgments}

I wish to thank An Weizhu for drawing the picture of Lampas weave and Weave with supplementary wefts.

\section{References}

Dode, Z. (2005). Determination of Chinese, Iranian and Central Asian artistic tradition in the décor of silks of the Mongolian period from the Golden Horde legacy in Ulus Djuchi. Silk Road and Mongol-Yuan Art Paper collection of the international symposium (pp. 265-278). Hong Kong: ISAT/Costume Squad Ltd.

Folsach, K. V., \& Bersted, A. M. K. (1993). Woven Treasures-Textiles from world of Islam. Copenhagen. The David Collecton.

Shang, G. (1999). Arts and Crafts History of Yuan Dynasty. Shenyang: Liaoning Education Press.

Watt, J. C. Y., \& Wardwell, A. E. (1997). When Silk Was Gold. New York. The Metropolitan Museum of Art.

Ye, Z. Q. (1959). Za Zhi Pian. Cao Mu Zi. Beijing: Zhonghua Book Company.

Yu, J. (1937). Dao yuan xue gu lu. Shanghai: The Commercial Press.

Zhao, F. (2005). Chinese silk. Suzhou: Soochow University Press.

Zhao, F. (2005). Gold/Silk/Blue and White Porcelain Fascinating Art of Marco Polo Era. Hong Kong: ISAT/Costume Squad Ltd.

Zhao, F. (2006). The type and position of the Mongol and Yuan imperial robe. Cultural Relics, (8), 85-96.

Zheng, G. (2002). The Original LaoQiDa. Beijing: Foreign Language Teaching and Research Press.

\section{Copyrights}

Copyright for this article is retained by the author(s), with first publication rights granted to the journal.

This is an open-access article distributed under the terms and conditions of the Creative Commons Attribution license (http://creativecommons.org/licenses/by/4.0/). 